\title{
Miocene cyclopid copepod from a saline paleolake in Mojave, California
}

\author{
Maria Hołyńska, Leroy Leggitt, and Alexey A. Kotov \\ Acta Palaeontologica Polonica 61 (2), 2016: 345-361 doi:http://dx.doi.org/10.4202/app.00137.2014
}

There are remarkably few direct fossil records of Copepoda, which implies that current estimates of the lineage divergence times and inferences on the historical biogeography remain highly dubious for these small-sized crustaceans. The Cyclopidae, a predominantly freshwater copepod family with 1000+ species and distributed worldwide, has no fossil record at all. Recent collections from the middle Miocene Barstow Formation in Southern California resulted in ample material of finely preserved cyclopid fossils, including both adult and larval stages. To document the antennulary setation pattern in the adult and copepodid instars we used a coding system that is coherent between sexes and developmental stages. The majority of the cyclopid fossils, coming from saline lake environment, represent the modern genus Apocyclops, a euryhaline, thermophilic group occurring both in the New World and Old World. A new species Apocyclops californicus is described, based on the short medial spine and spiny ornamentation of the free segment of leg 5, spinule ornamentation of pediger 5, and well-developed protuberances of the intercoxal sclerite of leg 4 . The presence of antennal allobasis and the features of the swimming legs unambiguously place the Miocene Apocyclops in the A. panamensis-clade, a predominantly amphi-Pacific group. The middle Miocene fossils with clear affinities to a subgroup of Apocyclops imply an early Miocene or Paleogene origin of the genus. Based on the geographic patterns of the species richness and morphology in Apocyclops and its presumed closest relative, genus Metacyclops, we hypothesize that: (i) the ancestor of Apocyclops, similar in morphology to some cave-dweller Metacyclops occurring today in the peri-Mediterranean region, might have arrived in North America from Europe via the Thulean North Atlantic bridge in the late Paleocene-early Eocene; (ii) Eocene termination of the Thulean land connection might have resulted in the divergence of Apocyclops from the Metacyclops stock.

Key words: Copepoda, Cyclopidae, ontogeny, biogeography, saline lake, Miocene, Barstow Formation, amphi-Pacific.

Maria Hołyńska [mariahol@ miiz.waw.pl], Museum and Institute of Zoology, Polish Academy of Sciences, Wilcza 64, 00-679 Warszawa, Poland. Leroy Leggitt [1leggitt@llu.edu ], Department of Earth and Biological Sciences, Loma Linda University, Loma Linda CA 92350, USA. Alexey A. Kotov [alexey-a-kotov@yandex.ru], A.N. Severtsov Institute of 
Ecology and Evolution, Leninsky Prospect 33, Moscow 119071, Russia; Kazan Federal University, Kremlevskaya 18., Kazan 420000, Russia.

This is an open-access article distributed under the terms of the Creative Commons

Attribution License (for details please see creativecommons.org), which permits unrestricted use, distribution, and reproduction in any medium, provided the original author and source are credited.

Fof Full text $(1,387.1 \mathrm{kB})$ ।

For Supplementary file $(1,081.9 \mathrm{kB})$ 